\title{
Diagnostic challenges in a case of reactive arthritis with concurrent calcium pyrophosphate disease
}

\author{
Andra Carmina Ciotoracu', Constantin-Ioan Busuioc ${ }^{2}$, Andreea Alexandra Nicola', \\ Paul Miron-Basalic ${ }^{1}$, Mihai-Marian Rusei', Madalina Duna', Narcis Copca ${ }^{3}$, Denisa Predeteanu' ${ }^{1,4}$ \\ ${ }^{1}$ Department of Rheumatology and Internal Medicine, "Sf. Maria" Clinical Hospital, Bucharest, Romania \\ ${ }^{2}$ Department of Pathology, Anatomy and Laboratory, "Sf. Maria" Clinical Hospital, Bucharest, Romania \\ ${ }^{3}$ Department of Surgery and Transplantation, "Sf. Maria" Clinical Hospital, Bucharest, Romania \\ 4 "Carol Davila" University of Medicine and Pharmacy, Bucharest, Romania
}

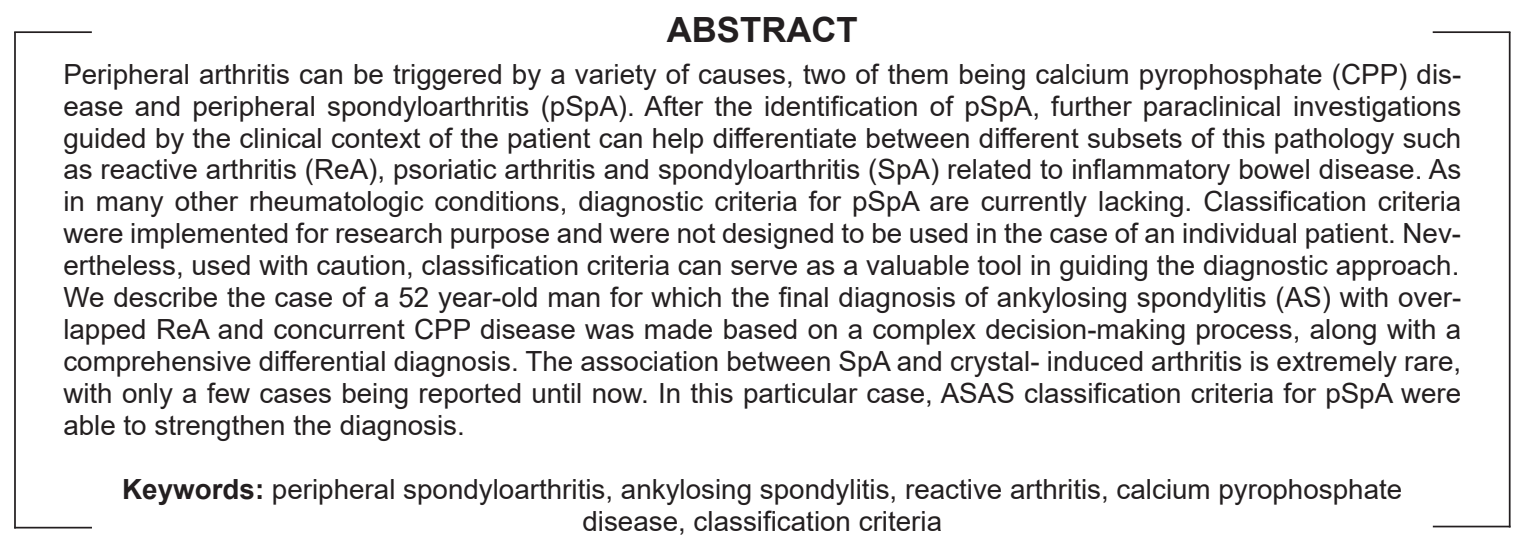

\section{INTRODUCTION}

Peripheral arthritis can be triggered by a variety of causes and, most of the times, the diagnostic workup is laborious, necessitating a careful anamnesis and physical examination of the patient along with several paraclinical investigations. At the same time, the epidemiological background in disease development should not be overlooked. Degenerative, infectious, autoimmune, malignant, traumatic, metabolic and idiopathic etiologies should be considered in the differential diagnosis of peripheral arthritis, as it will be illustrated in the following case report of a patient diagnosed with peripheral spondyloarthritis (pSpA) and concurrent calcium pyrophosphate (CPP) disease. Proper diagnostic criteria, which are a set of symptoms, sings and tests implemented in order to guide the clinician in making the positive diagnosis in an individual patient, are lacking for most rheumatologic conditions due to their heterogeneity.

In contrast to diagnostic criteria, classification criteria are implemented to facilitate the inclusion of a homogenous cohort in research studies, but were not designed to be used for diagnostic purpose of musculoskeletal diseases. Nevertheless, classification criteria can be a valuable tool and can come in the aid of the clinician in certain situations.

Over the years several criteria that measure or comprise indicators of inflammatory back pain in the clinical evaluation were developed, specifically in ankylosing spondylitis (AS). Chronologically, inflammatory back pain was included in Rome criteria (1961), in New York criteria (1966), in Calin criteria 
(1977), in the modified New York criteria (1984) and later in Berlin criteria $(2006)(1,2)$.

The first classification criteria for spondyloarthritis, Amor criteria (1990) and The European Spondyloarthropathy Study Group (ESSG) criteria (1991), were designed to increase the sensitivity and specificity in classifying spondyloarthropathies $(3,4)$. Overtime, with a better understanding of disease pathophysiology and with improvements in imaging techniques, new classification criteria had to be elaborated, as was the case with SpA. Thus, between 2009 and 2011, the Assessment of Spondyloarthritis International Society (ASAS) has published new classification criteria, which distinguish between axial $\mathrm{SpA}(\mathrm{axSpA})$ and peripheral $\mathrm{SpA}(\mathrm{pSpA})$ based on the predominant axial or peripheral involvement. The criteria for $\mathrm{pSpA}$ consist of peripheral arthritis and/or enthesitis and/or dactylitis plus some additional features. The patient may present one or more of the following features: uveitis, psoriasis, inflammatory bowel disease, preceding infection, human leukocyte antigen (HLA)-B27 or sacroiliitis on imaging. As an alternative, the patient may present two or more of the following features: arthritis, enthesitis, inflammatory back pain in the past, dactylitis or family history of SpA (5-7). After the identification of $\mathrm{pSpA}$, further paraclinical investigations guided by the clinical context of the patient can help differentiate between the three different subsets of this pathology: reactive arthritis (ReA), psoriatic arthritis and SpA related to inflammatory bowel disease.

As for axSpA, two subtypes are currently recognised: AS (with sacroiliitis on plain radiography, according to definitions of the modified New York criteria) and non-radiographic $\operatorname{axSpA}(2)$. In contrast with ASAS classification criteria for $\mathrm{pSpA}$, where the age of the patient is not included, the entry criterion for axSpA is the age at onset of less than 45 years.

As mentioned before, acute inflammatory attacks in peripheral articulations can also be triggered by deposition of different types of crystals, such as monosodium urate crystals or CPP crystals. CPP disease was first described over 50 years ago, in the early 1960 'ties, by McCarty et al. (8). Over 200 synovial fluids were analysed by phase contrast and polarized light microscopy. Along with the description of optical characteristics of the crystals, there was also a detailed depiction of the clinical manifestations and radiographical findings of the CPP disease $(9,10)$. Later on, in 2011, the European League
Against Rheumatism (EULAR) worked towards developing a consensus regarding terminology, diagnosis and management of CPP deposition and published a set of recommendations $(11,12)$.

The association between SpA and crystal-induced arthritis, as presented in this paper, is extremely rare, with only a few cases being reported until now.

\section{CASE REPORT}

We present the case of a 52 year-old man with known and well-controlled diabetes and arterial hypertension, who was hospitalized in our department for myalgia and severe muscle weakness, fatigue and who developed during the hospital stay multiple debilitating asymmetric arthritides. He also reported occasional inflammatory hip and low back pain. The first symptoms appeared approximately 3 months prior to admission, with progressive worsening and development of physical impairment. From his medical history, it is worth mentioning that, some weeks before the onset of the articular symptoms, the patient described an episode of nausea, abdominal cramping, fever and one loose stool, for which he had been hospitalized, diagnosed with acute gastroenteritis and treated with ciprofloxacin $500 \mathrm{mg}$ twice a day, for 7 days.

The physical examination at admission confirmed the muscle weakness, especially in the lower limbs, and revealed several swollen joints (both knees Figure 1A, right shoulder and right ankle - Figure 1B) accompanied by local pain, redness and warmth. No limitation of spinal mobility or chest expansion was found.

Laboratory tests were in correlation with the clinical manifestations, showing important inflammatory syndrome, increased ferritin level, low serum iron concentration and mild normocytic anemia (Figure 2A). Serum protein electrophoresis showed a mild decrease in albumin level and an increase in alpha fraction, as a marker of inflammation.

The diagnostic workup was complex and several pathologies had to be excluded before the final diagnosis to be made. Possible conditions that were included in the differential diagnosis consisted of inflammatory muscle disease, malignant etiology, septic arthritis, rheumatoid arthritis, polymyalgia rheumatica, ReA and CPP disease and were subsequently investigated.

Two weeks before admission, the patient had been evaluated in another medical department where he underwent abdominal ultrasound and computer to- 

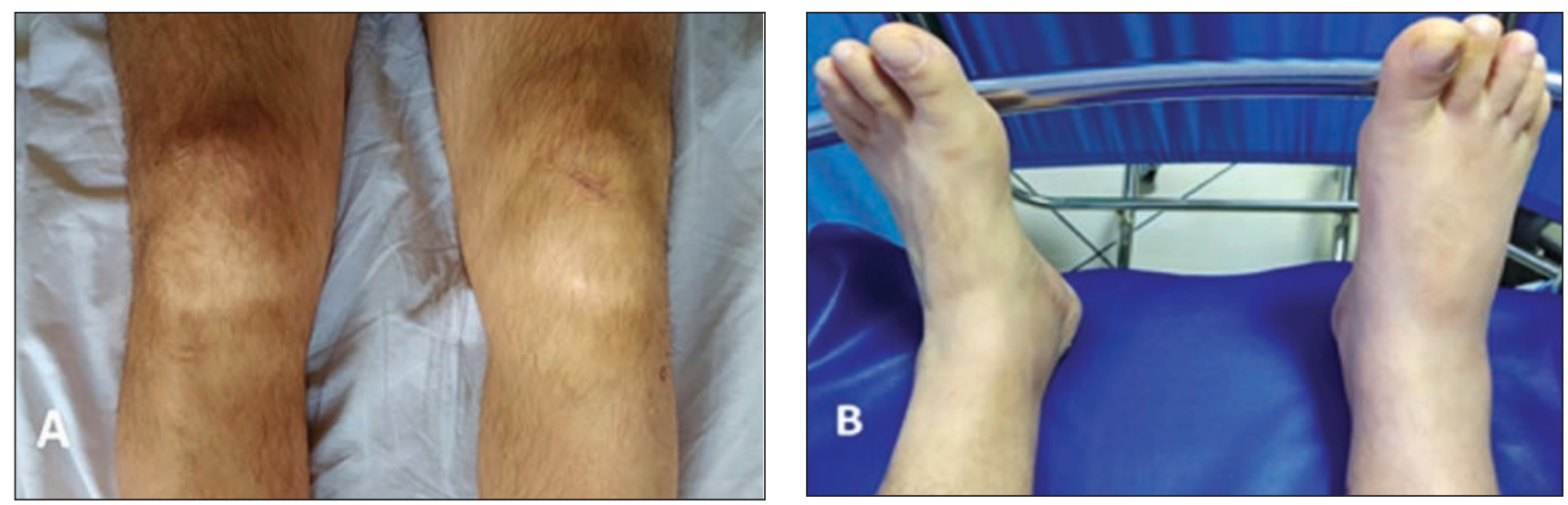

FIGURE 1. (A) Bilateral knee joint swelling. (B) Right ankle joint swelling)

mography of the chest, abdomen and pelvis, as well as upper endoscopy and colonoscopy, without any relevant finding. After ruling out a malignant etiology, electrophysiological tests were performed and the result did not orientate towards inflammatory muscle disease. In addition, muscle enzymes were normal and the myositis antibody panel was negative. Rheumatoid factor was absent and uric acid level fell within reference range. The synovial fluid obtained from two ultrasound-guided aspiration procedures was analysed and the culture did not identify any infectious pathogen. The patient was afebrile during the hospitalisation. Cardiac ultrasound was also performed in order to rule out endocarditis.

Furthermore, even though the culture from the synovial fluid was negative, its analysis proved to be essential in the diagnostic process. Microscopic examination revealed inflammatory cells and immunological test revealed negative rheumatoid factor but

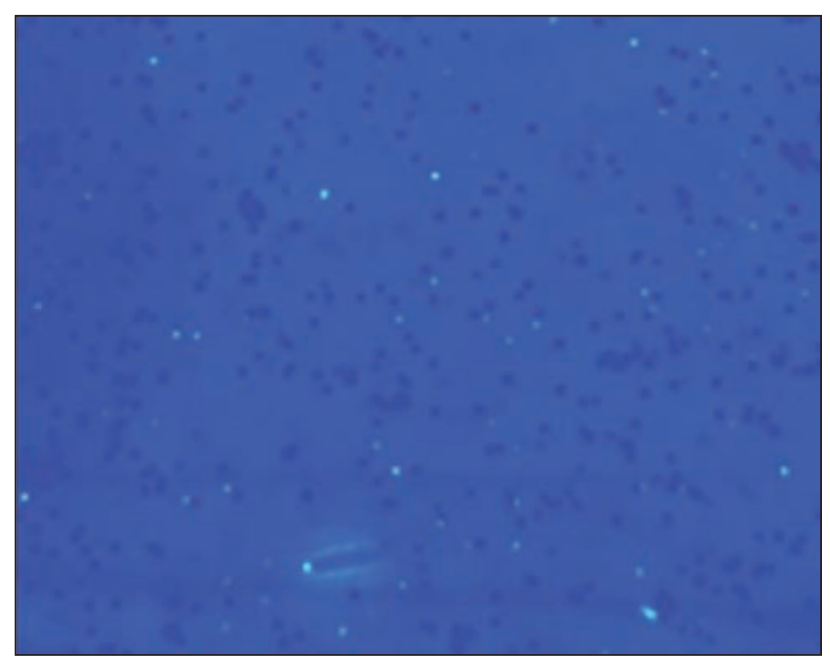

FIGURE 2. Microscopic analysis of the synovial fluid (polarized light microscopy).

Synovial fluid smear with frequent polymorphonuclear cells, rare synoviocytes. Polarized light microscopy: short, rhomboidal and positively birefringent crystals, suggestive for CPP crystals when the polarized light technique was used, the synovial fluid showed multiple crystals with a positive sign of birefringence and with a suggestive shape for CPP crystals (Figure 2B).

TABLE 1. Relevant laboratory findings - initial and one month later results

\begin{tabular}{|c|c|c|c|}
\hline $\begin{array}{c}\text { Blood } \\
\text { test }\end{array}$ & $\begin{array}{c}\text { Initial } \\
\text { result }\end{array}$ & $\begin{array}{c}1 \text { month } \\
\text { later }\end{array}$ & Normal value \\
\hline Hemoglobin & $11.3 \mathrm{~g} / \mathrm{dl}$ & $10.5 \mathrm{~g} / \mathrm{dl}$ & $13-17.5 \mathrm{~g} / \mathrm{dl}$ \\
\hline $\mathrm{MCV}$ & $88.4 / \mathrm{fL}$ & $85.1 / \mathrm{fL}$ & $78-100 / \mathrm{fL}$ \\
\hline $\mathrm{MCH}$ & $28.5 / \mathrm{pg}$ & $28.0 / \mathrm{pg}$ & $26.5-34 / \mathrm{pg}$ \\
\hline $\mathrm{CRP}$ & $159 \mathrm{mg} / \mathrm{l}$ & $98.17 \mathrm{mg} / \mathrm{l}$ & $0-5 \mathrm{mg} / \mathrm{l}$ \\
\hline $\mathrm{ESR}$ & $112 \mathrm{~mm} / \mathrm{h}$ & $42 \mathrm{~mm} / \mathrm{h}$ & $2-20 \mathrm{~mm} / \mathrm{h}$ \\
\hline Fibrinogen & $671 \mathrm{mg} / \mathrm{dl}$ & - & $170-420 \mathrm{mg} / \mathrm{dl}$ \\
\hline Ferritin & $601 \mu \mathrm{g} / \mathrm{l}$ & - & $20-250 \mu \mathrm{g} / \mathrm{l}$ \\
\hline Serum iron & $27 \mu \mathrm{g} / \mathrm{dl}$ & $34 \mu \mathrm{g} / \mathrm{dl}$ & $70-180 \mu \mathrm{dl}$ \\
\hline $\begin{array}{c}\text { Blood } \\
\text { test }\end{array}$ & $\begin{array}{c}\text { Initial } \\
\text { result }\end{array}$ & $\begin{array}{c}1 \mathrm{month} \\
\text { later }\end{array}$ & Normal value \\
\hline $\begin{array}{c}\text { Anti-Salmonel- } \\
\text { la antibodies }\end{array}$ & $\begin{array}{c}1 / 320 \\
\text { Anti- } \\
\text { Salmonella } \\
\text { agglutinins; } \\
\text { BO, DO. }\end{array}$ & - & Negative $\leq 1 / 80$ \\
\hline HLA B-27 & $\begin{array}{c}\text { Positive } \\
\text { M }\end{array}$ & - & \\
\hline
\end{tabular}

$M C V=$ mean corpuscular volume $C R P=C$-reactive protein $; E S R=$ eryth rocyte sedimentation rate;

As the patient mentioned an episode of loose stool before symptoms' onset and knowing that ReA with an intestinal or genital trigger can also display acute episodes of peripheral arthritis, some of the frequently involved etiologies were investigated. Tests for hepatitis and HIV were negative, as potential viral causes. With regard to gastrointestinal and genital triggers, the patient tested negative for Chlamydia trachomatis, Yersinia and Helicobacter pylori antibodies, while Salmonella antibodies were found positive (Figure 2A). Prostate-specific antigen was in normal range.

It is worth to further emphasize that the patient did not complain about axial pain or other peripheral 
arthritides in the past years. Concerning the inflammatory hip and low back pain, even though it was not as debilitating as the peripheral arthritides, imaging investigations were employed. Sacroiliac (SI) joint radiography showed bilateral joint space narrowing and subchondral sclerosis, interpreted as bilateral grade III sacroiliitis (Figure 3(A)), suggesting an old, undiagnosed AS. Further magnetic resonance
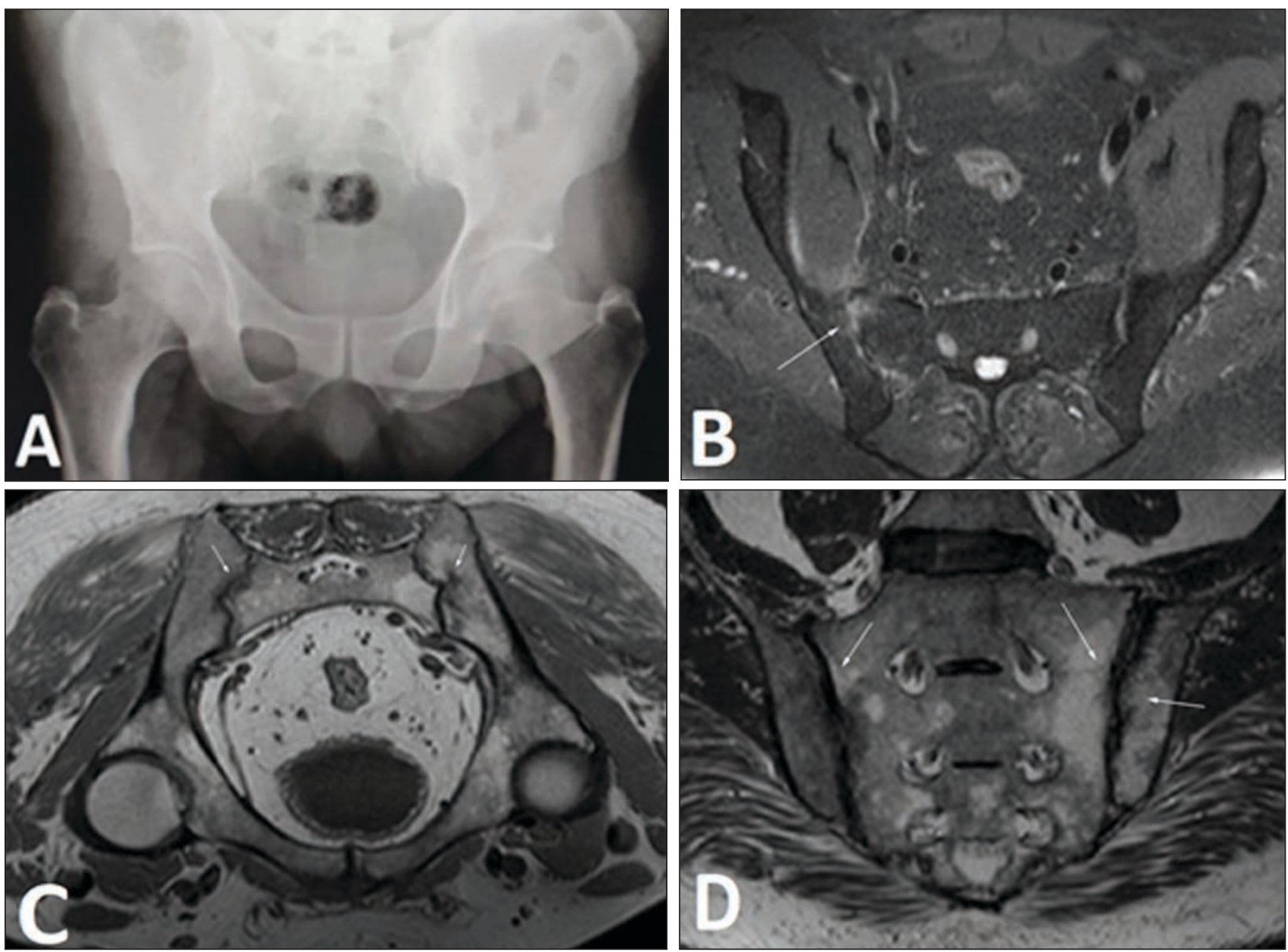

imaging (MRI) examination added useful information with the identification of inflammatory and structural lesions in the SI joints together with pelvic enthesitis. The MRI report described active inflammatory lesions of bone marrow edema and enthesitis, along with bilateral joint space narrowing, subchondral sclerosis and fat metaplasia (Figure 3(B)).

FIGURE 3. Imaging examinations of the patient. (A) Radiography of the pelvis (anterior-posterior projection); bilateral SI joint space narrowing and subchondral sclerosis. Bilateral grade III sacroiliitis. MRI of the SI joints (B, $C$ and D).

(B) PD-fat saturated, transverse view; Bone marrow edema of the right sacroiliac joint (white arrow) (C) T1 TSE, transverse view; SI joint space narrowing and bilateral hypointense signal in both margins of the SI joint (white arrows). (D) T2 TSE, coronal view. Fat metaplasia (white arrows) hyperintense signal - a sign of previous inflammation

Besides being a valuable tool in the joint aspiration procedure and in guiding the administration of intraarticular corticosteroid treatment, ultrasound examination showed Achilles enthesitis at the right ankle, which correlates well with the previously mentioned findings.

The likelihood of ReA explaining the clinical picture of the patient was further increased when he tested positive for HLA-B27. Moreover, when the test came back positive, he mentioned his sister was diagnosed years ago with HLA-B27 positive ankylosing 
day and colchicine $1 \mathrm{mg}$ per day. A 10 day-course for two consecutive months of antibiotic treatment with ciprofloxacin $500 \mathrm{mg}$ twice a day was associated. Alongside the above mentioned treatment, the patient received his usual antihypertensive and antidiabetic drugs. One month later, the patient still reported inflammatory pain in the joints. Laboratory tests revealed a slight improvement compared with the initial ones (Figure 2A), but without a major change in regard to the biological inflammatory syndrome.

\section{DISCUSSIONS}

Prompt identification and treatment of ReA and CPP disease can be challenging for many reasons, as was illustrated in the above case, where multiple diseases had to be excluded. The final diagnosis was made based on a complex decision-making process conducted by the clinician.

To begin with, there are no validated diagnostic criteria for $\mathrm{pSpA}$ and there is no gold-standard test to be performed. Moreover, several diagnostic criteria have been proposed for ReA, but to date none of them has been validated (13). Thus, the diagnosis is based on the clinical presentation and exclusion of other possible causes (Figure 4) (14). Rheumatologic diseases usually progress over a long period of time and have multisystem involvement, with heterogeneous manifestations. Therefore, only an experienced medical professional is able to make a correct diagnosis by putting together all the findings. When diagnostic criteria are lacking, if used carefully, classification criteria could serve as diagnostic criteria when applied in a similar setting, such as in a rheumatology department where patients suspected of spondyloarthritis (SpA) are usually referred to (15). Even though classification criteria are generally applied on a group of patients and were designed for research purposes only, in specific situations, after ruling out other possibilities, they could facilitate the diagnosis in an individual patient. In regard to the presented case, looking over the ASAS classification criteria for pSpA published in 2011, the patient had 6 features framed in the classification of this pathology. He had multiple arthritides, inflammatory low back pain, familial history of SpA, enthesitis on ultrasound and MRI images and a positive result for HLA-B27. He also had an enteric infection with positive Salmonella antibodies before the onset of articular symptoms. As the patient reported, his inflammatory back pain along with all the peripheral arthritides firstly appeared 3 months prior to hospital admission, at the age of 52. Looking back to the whole clinical pres- entation, after the investigative workup is complete, in this particular case, ASAS classification criteria for pSpA were able to strengthen the diagnosis.

Furthermore, as mentioned above, rheumatologic conditions progress throughout several years, having different evolution stages in which clinical features may change and new findings come to surface. This explains why frequently conventional radiography of the SI appears to be normal in spite of the pain described by the patients. With the introduction of MRI technology in the late 1900'ties, major improvements have been made in the diagnosis and monitoring of structural changes and also in predicting the effect of a specific treatment. MRI allows the early identification of inflammatory changes in SpA, years before radiographic sacroiliitis becomes detectable and even before having a corresponding symptom. Being such a valuable tool, in 2009 ASAS/OMERACT MRI group has published a consensus describing frequent MRI findings that could help clarify the term ,active sacroiliitis by MRI" in aSpA (16). Moreover, MRI was introduced in both axSpA and pSpA classification criteria and used since then for research and diagnostic purposes (6). In our patient's case, the conventional radiograph showed bilateral SI joint space narrowing and subchondral sclerosis suggestive for grade III sacroiliitis, while the MRI was useful in revealing active inflammation represented by bone marrow oedema and enthesitis, as well as structural damage lesions characterized by subchondral sclerosis and periarticular fat deposition. Findings in the MRI of our patient were compatible with the description of lesions from the ASAS/OMERACT MRI consensus (16).

ReA can be self-limiting, or when it lasts for more than 6 months, can progress towards a chronic arthritis with possible development of sacroiliitis and even ankylosing spondylitis (AS). Some of the factors thought to be responsible for its highly variable evolution are represented by the triggering infectious pathogen, the genetic background of the patient, the positive family history for SpA or AS and by a persistent intestinal inflammation $(13,17,18)$. Another possible scenario, which applied to our patient, is the occurrence of ReA in someone who has already developed asymptomatic AS and has a predisposing terrain with a family history of SpA and positive HLA-B27. The grade III sacroiliitis detected on the radiography along with the MRI findings showing active inflammation with chronic lesions background raised the hypothesis of a pre-existing AS that was undiagnosed and left un- 
treated. Whether the superposition of a ReA could accelerate the destructive process is a question whose answer will be given only by a long term follow-up. Prompt therapeutic decisions are essential in the at- tempt to retard structural damage progression and the possibility of initiating a biologic drug can be assessed in accordance with the national guideline for biologic therapy.

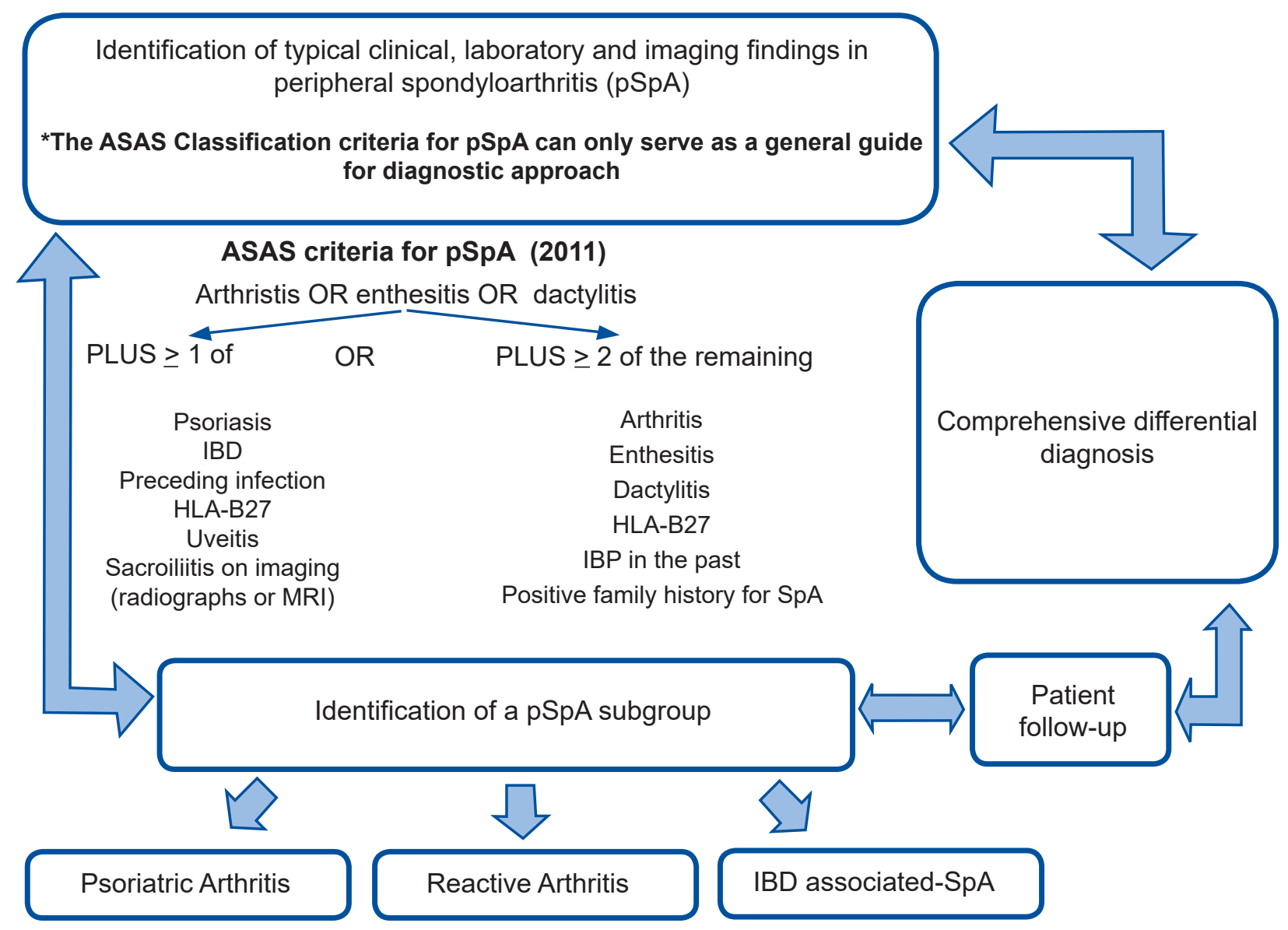

MRI - Magnetic resonance imaging; IBD-inflammatory bowel disease; IBD-back pain; SpA-spondyloarthritis; pSpA-peripheral spondyloarthritis.

FIGURE 4. A possible approach in the diagnosis of $p \operatorname{SpA}(6,14)$

ReA can be self-limiting, or when it lasts for more than 6 months, can progress towards a chronic arthritis with possible development of sacroiliitis and even ankylosing spondylitis (AS). Some of the factors thought to be responsible for its highly variable evolution are represented by the triggering infectious pathogen, the genetic background of the patient, the positive family history for SpA or AS and by a persistent intestinal inflammation $(13,17,18)$. Another possible scenario, which applied to our patient, is the occurrence of ReA in someone who has already developed asymptomatic AS and has a predisposing terrain with a family history of $\mathrm{SpA}$ and positive HLA-B27. The grade III sacroiliitis detected on the radiography along with the MRI findings showing active inflammation with chronic lesions background raised the hypothesis of a pre-existing AS that was undiagnosed and left untreated. Whether the superposition of a ReA could accelerate the destructive process is a question whose answer will be given only by a long term follow-up. Prompt therapeutic decisions are essential in the attempt to retard structural damage progression and the possibility of initiating a biologic drug can be assessed in accordance with the national guideline for biologic therapy.

Another challenge was whether to recommend or not antibiotic treatment for the patient's severe ReA, as data obtained from various studies is contradictory, some suggesting no effect on articular manifestations once the ReA is triggered. Generally, antibiotic treatment is recommended in ReA triggered by sexual transmitted pathogens, for instance Chlamydia trachomatis. As for ReA caused by an enteric infection, one study suggested that a three months course of ciprofloxacin treatment was associated with a shorter persistence of circulating IgA against Yersinia outer membranes proteins and with the Yersinia enterocolitica elimination from the intestinal lymphoid tissue 
based on antigen detection (19). Two other studies suggest that even though a three months course of ciprofloxacin did not have any beneficial effects during the 12 months follow up (20), on a 4-7 year follow up it might facilitate complete recovery and it might lower the chances of developing a chronic disease, especially in the HLA-B27 positive patients (21). Indeed, further studies are needed to clarify the efficacy of ciprofloxacin treatment and the optimal approach in severe cases of ReA with intestinal trigger or in cases of chronic Salmonella carriage.

The definite diagnosis of CPP disease is based on the identification of CPP crystals in the synovial fluid (12). The EULAR consensus regarding the management of CPP disease recommends besides temporary rest, also the administration of intra-articular long-acting GC along with oral administration of both NSAIDs and low-dose colchicine (11). In the context of associated ReA, in addition to the conventional treatment consisting of NSAIDs and intra-articular GC, sulfasalazine, a disease-modifying anti-rheumatic drug was added for our patient.

Last but not least, the association of both pathologies, SpA and crystal-induced arthritis makes the presented case especially distinctive, as only a few cases have been reported until now. Some case reports describe the association between psoriatic arthritis and crystal-induced arthritis, in particular gout (22-25). A case-control study found that gout is not less common in a population of AS patients compared to the general population. The two pathologies might share similar pathogenic mechanisms, which could explain their coexistence (26). Another study suggests gout prevalence may be underestimated among patients diagnosed with AS due to chronic use of NSAIDs

\section{REFERENCES}

1. Weisman $\mathrm{MH}$. Inflammatory back pain: the United States perspective. Rheum Dis Clin North Am. 2012;38(3):501-12.

2. van der Linden $S$, Valkenburg $H A$, Cats $A$. Evaluation of diagnostic criteria for ankylosing spondylitis. A proposal for modification of the New York criteria. Arthritis Rheum. 1984;27(4):361-8.

3. Wendling D, Prati C, Toussirot E, Ornetti P. Spondylarthrite, spondylarthropathies: critères de diagnostic et de classification. Revue du Rhumatisme Monographies 2010;77(1):43-47.

4. Dougados $M$, van der Linden $S$, Juhlin R, Huitfeldt $B$, Amor B, Calin A, Cats A, Dijkmans B, Olivieri I, Pasero G, et al. The European Spondylarthropathy Study Group preliminary criteria for the classification of spondylarthropathy. Arthritis Rheum. 1991;34(10):1218-27.

5. Rudwaleit M, van der Heijde D, Landewé R, Listing J, Akkoc N, Brandt J, Braun J, Chou CT, Collantes-Estevez E, Dougados M, Huang F, Gu J, Khan MA, Kirazli Y, Maksymowych WP, Mielants $H$, Sørensen IJ, Ozgocmen S, Roussou E, Valle-Oñate R, Weber U, Wei J, Sieper J. The development of Assessment of that could potentially mask an acute episode of gout (27). As for CPP disease, further studies are needed to assess its prevalence in SpA patients.

\section{CONCLUSIONS}

This case stands out because it was able to illustrate how classification criteria for $\mathrm{pSpA}$, if used carefully, can come to the aid of the physician when managing the case of an individual patient. The diagnostic approach should always encompass a complete medical history and physical evaluation, multiple laboratory tests, and if considered necessary, imaging examinations, as well as a comprehensive differential diagnosis. Only then, the clinician can use the classification criteria to strengthen the final diagnosis. Afterwards, if all findings point towards $\mathrm{pSpA}$, further investigations will be required in order to place it in one of the following specific subsets: ReA, psoriatic arthritis and SpA related to inflammatory bowel disease. This was the case of our patient, who was diagnosed with ReA triggered by a gastrointestinal Salmonella infection. The occurrence of ReA in a patient who has a HLA B27 and has already developed asymptomatic AS is possible. Long term follow-up is essential as ReA could accelerate the destructive process already started.

In addition, another aspect that makes this case distinctive is the unusual association of ReA and CPP disease that led to many challenges in the diagnostic and management process.

Hopefully, in the future, case reports similar to this one will facilitate a better understanding of diseases and together with extensive evidence-based research, will address the need of developing diagnostic criteria for some rheumatologic conditions.

Conflict of interest: none declared Financial support: none declared

SpondyloArthritis international Society classification criteria for axial spondyloarthritis (part II): validation and final selection. Ann Rheum Dis. 2009;68(6):777-83.

6. Rudwaleit M, van der Heijde D, Landewé R, Akkoc N, Brandt J, Chou CT, Dougados M, Huang F, Gu J, Kirazli Y, Van den Bosch F, Olivieri I, Roussou E, Scarpato S, Sørensen IJ, Valle-Oñate R, Weber U, Wei J, Sieper J. The Assessment of SpondyloArthritis International Society classification criteria for peripheral spondyloarthritis and for spondyloarthritis in general. Ann Rheum Dis. 2011;70(1):25-31.

7. Rostom S, Dougados M, Gossec L. New tools for diagnosing spondyloarthropathy. Joint Bone Spine. 2010;77(2):108-14.

8. Hollander JL, Jessar RA, McCarty DJ. Synovianalysis: an aid in arthritis diagnosis. Bull Rheum Dis. 1961;12:263-4.

9. McCarty DJ, Faires JS, Kohn NN. The significance of calcium pyrophosphate crystals in the synovial fluid of arthritis patients: the "pseudogout syndrome". I. Clinical Aspects. Ann Intern Med. 1962;56:711-737. 
10. Kohn NN, Hughes RE, McCarty DJ Jr, Faires JS. The significance of calcium phosphate crystals in the synovial fluid of arthritic patients: the "pseudogout syndrome". II. Identification of crystals. Ann Intern Med. 1962;56:738-45.

11. Zhang W, Doherty M, Pascual E, Barskova V, Guerne PA, Jansen TL, Leeb BF, Perez-Ruiz F, Pimentao J, Punzi L, Richette P, Sivera F, Uhlig T, Watt I, Bardin T. EULAR recommendations for calcium pyrophosphate deposition. Part II: management. Ann Rheum Dis. 2011;70(4):571-5.

12. Zhang W, Doherty M, Bardin T, Barskova V, Guerne PA, Jansen TL, Leeb BF, Perez-Ruiz F, Pimentao J, Punzi L, Richette P, Sivera F, Uhlig T, Watt I, Pascual E. European League Against Rheumatism recommendations for calcium pyrophosphate deposition. Part I: terminology and diagnosis. Ann Rheum Dis. 2011;70(4):563-70

13. Bentaleb I, Abdelghani K, Rostom S, Amine B, Laatar A, Bahiri R. Reactive Arthritis: Update. Current Clinical Microbiology Reports 2020;7:1-9.

14. Yu DT, van Tubergen A. Clinical manifestations and diagnosis of peripheral spondyloarthritis in adults. Avalable at: https://www. uptodate.com/contents/clinical-manifestations-and-diagnosis-ofperipheral-spondyloarthritis-in-adults.

15. van den Berg R, van der Heijde DM. How should we diagnose spondyloarthritis according to the ASAS classification criteria: a guide for practicing physicians. Pol Arch Med Wewn. 2010;120(11):452-7.

16. Rudwaleit M, Jurik AG, Hermann KG, Landewé R, van der Heijde D, Baraliakos X, Marzo-Ortega H, Ostergaard M, Braun J, Sieper J. Defining active sacroiliitis on magnetic resonance imaging (MRI) for classification of axial spondyloarthritis: a consensual approach by the ASAS/OMERACT MRI group. Ann Rheum Dis. 2009;68(10):1520-7.
17. Hannu T, Inman R, Granfors K, Leirisalo-Repo M. Reactive arthritis or post-infectious arthritis? Best Pract Res Clin Rheumatol. 2006;20(3):419-33

18. Leirisalo-Repo M, Helenius P, Hannu T, Lehtinen A, Kreula J, Taavitsainen M, Koskimies S. Long-term prognosis of reactive salmonella arthritis. Ann Rheum Dis. 1997;56(9):516-20.

19. Hoogkamp-Korstanje JA, Moesker H, Bruyn GA. Ciprofloxacin v placebo for treatment of Yersinia enterocolitica triggered reactive arthritis. Ann Rheum Dis. 2000;59(11):914-7.

20. Yli-Kerttula T, Luukkainen R, Yli-Kerttula U, Möttönen T, Hakola M, Korpela M, Sanila M, Parviainen J, Uksila J, Vainionpää R, Toivanen A. Effect of a three month course of ciprofloxacin on the outcome of reactive arthritis. Ann Rheum Dis. 2000;59(7):565-70.

21. Yli-Kerttula T, Luukkainen R, Yli-Kerttula U, Möttönen T, Hakola M, Korpela M, Sanila M, Uksila J, Toivanen A. Effect of a three month course of ciprofloxacin on the late prognosis of reactive arthritis. Ann Rheum Dis. 2003;62(9):880-4.

22. Turan $Y$, Kocaağa Z, Koçyiğit $H$, Gürgan A, Korhan B. Coexistence of Psoriatic Spondyloarthropathy and Gout: A Case Report. Archives of Rheumatology 2009;24(3):159-162.

23. De Bari C, Lapadula G, Cantatore FP. Coexisting psoriatic arthritis, gout, and chondrocalcinosis. Scand J Rheumatol. 1998;27(4):306-9.

24. Coexisting Ankylosing Spondylitis and Gouty Arthritis. Yildiz N, Sutbeiaz ST, Koseoglu F. Turk J Phys Med Rehab 2011;57:111-3.

25. Leonard DG, O'Duffy JD, Rogers RS. Prospective analysis of psoriatic arthritis in patients hospitalized for psoriasis. Mayo Clin Proc. 1978;53(8):511-8.

26. Gonen $T$, Tiosano $\mathrm{S}$, Comaneshter $\mathrm{D}$, Amital $\mathrm{H}$, Cohen $\mathrm{AD}$, Shovman $\mathrm{O}$. The coexistence of gout in ankylosing spondylitis patients: a case control study. Rheumatol Int. 2020;40(3):465-470.

27. Ho HH, Yu KH, Chen JY, Lin JL, Wu YJ, Luo SF, Liou LB. Coexisting ankylosing spondylitis and gouty arthritis. Clin Rheumatol. 2007;26(10):1655-61. 